\title{
EDITORIAL
}

\section{RECENT DEVELOPMENTS IN CLAY MINERAL APPLICATIONS}

This issue of Clay Minerals contains eight papers presented at a meeting of the Clay Minerals Group of the Mineralogical Society, which was held at the University College of Wales, Aberystwyth on 29 March 1983 and organized by Dr J. M. Adams. Also included are two extra papers directly relevant to the theme of this meeting which, in bringing together chemists, mineralogists and materials scientists with both industrial and academic backgrounds, will undoubtedly have stimulated further research in two already very active areas-catalysis by clay minerals and applications of clay/organic complexes. Publication has been supported financially by the British Petroleum Company p.l.c., English China Clays p.l.c., Imperial Chemical Industries p.l.c. and Wiggins Teape Research \& Development Ltd.

\section{PUBLICATION PROGRAMME FOR 1984}

The present issue is the second to be devoted to the proceedings of a thematic meetingthe first was volume 17 number 1 which contained papers presented at a meeting on 'clays in the discovery and recovery of petroleum' (Cambridge, April 1981). Volume 19 (1984) will include two thematic issues entitled 'patterns of mineral diagenesis on the NW European shelf and their relations to facies and hydrocarbon accumulation' (Cambridge, April 1983) and 'clays, minerals and thermal analysis-a tribute to R. C. Mackenzie' (London, November 1983). In order not to delay publication of papers received in the normal manner, volume 19 will consist of five issues which will be published in February, April, June, September and December.

\section{ABSTRACT TRANSLATIONS}

Since 1976, papers published in any of the four official languages of the journal-English, French, German and Spanish - have included abstracts in the three other languages. However, at a meeting of the Editorial Board held during the Fifth Meeting of the European Clay Groups in Prague, Czechoslovakia, it was agreed to discontinue abstract translations for a trial period of a year. The only exception will be when a paper is published in a language other than English; in this instance an English abstract will follow the abstract in the original language of the paper.

D J MORGAN 